\title{
Comparison of genotype and intellectual phenotype in untreated PKU patients
}

\author{
Susan J Ramus, Susan M Forrest, David B Pitt, Jennifer A Saleeba, \\ Richard G H Cotton
}

\begin{abstract}
We have screened 55 untreated phenylketonuria patients from 42 families for common mutations of the phenylalanine hydroxylase gene and determined both causative alleles in 12 families. The correlation between genotype and intellectual phenotype of patients in these families was examined. Our results were compared to a study which predicted phenylalanine hydroxylase activity based on genotype and examined its correlation with the biochemical phenotype of treated patients. Some of the intellectual phenotypes of patients in our study correlated well with the predicted activities. However, we found one family with a genotype expected to have no activity of phenylalanine hydroxylase where the patients were not severely retarded. Major differences in intellectual phenotype were found in patients with the same genotype both between unrelated subjects and within families, suggesting that there is not a simple correlation between genotype and intellectual phenotype.

(f Med Genet 1993;30:401-5)
\end{abstract}

Phenylketonuria (PKU) is an autosomal recessive genetic disorder caused by a deficiency in the liver specific enzyme phenylalanine hydroxylase (PAH) which can lead to mental retardation if untreated. The disease was first observed in 1934 by Folling and treatment with a diet low in phenylalanine was started in 1954 by Bickel et al. In 1963 the Guthrie test was introduced for newborn screening of PKU. This made possible the early treatment of all affected subjects with a diet low in phenylalanine, thus preventing the mental retardation caused by PKU. ${ }^{1}$

In Victoria, Australia, all infants born since the start of 1961 were tested for PKU, initially with phenistix strips to test urine for the presence of phenylketones and then with the more reliable Guthrie blood test which detected raised phenylalanine levels. ${ }^{2}$ Mentally retarded subjects and sibs of PKU patients were also tested for PKU. ${ }^{34}$ From this screening a group of untreated PKU patients was identified $^{3}$ and we obtained blood samples from 55 untreated patients from 42 families. These subjects were born from 1917 to 1965, before reliable newborn screening was established, and, since they were untreated, they are expressing their true intellectual phenotype which ranges from normal intelligence to profound mental retardation.

PKU is an extremely heterogeneous disease both at the genotypic and phenotypic level. More than 50 different mutations have been identified in the PAH gene. ${ }^{5}$ At the phenotypic level, patients exhibit wide variation in phenylalanine tolerance if treated or, if untreated, wide variation in intellectual ability. ${ }^{6}$ Not all subjects with PKU are mentally retarded if untreated. ${ }^{48}$ Determining whether a relationship exists between phenotype and genotype is very important if diagnosis and treatment based on genotype is to be considered. With the current practice of treatment of all PKU patients it is no longer possible to examine the intellectual phenotype of patients and people have been forced to study the biochemical phenotype of treated patients.

Okano et al found a good correlation between the biochemical phenotype of treated patients (based on load tests) with predicted enzyme activity (based on genotype and expression studies). A study of untreated patients could not distinguish between the intellectual phenotypes (mental retardation) when measuring residual enzyme activity (based on load tests) or even direct measurement of activity by liver needle biopsies. ${ }^{10}$

Our group of untreated PKU patients provides us with a special opportunity to be able to examine whether there is a correlation between the intellectual phenotype and the genotype of PKU patients. By studying the same mutations examined by Okano et al, ${ }^{9}$ we can determine the genotypes of our untreated patients and compare the predicted enzyme activity with the intellectual phenotype.

\section{Methods}

Fifty-five untreated PKU patients from 42 families were assigned to a particular intellectual phenotype (degree of mental retardation), based on their Binet IQ score ${ }^{3}$ (table 1).

Genomic DNA was prepared from blood samples ${ }^{11}$ and $1 \mu \mathrm{g}$ was amplified by polymerase chain reaction (PCR) using the following final conditions: $0.2 \mathrm{mmol} / 1 \mathrm{dNTPs}, 67 \mathrm{mmol} /$ 1 Tris- $\mathrm{HCl} \mathrm{pH} \mathrm{8.8,} 16.6 \mathrm{mmol} / 1\left(\mathrm{NH}_{4}\right)_{2} \mathrm{SO}_{4}$, $0.45 \%$ Triton X-100, $20 \mu \mathrm{g}$ gelatin, $1.5 \mathrm{mmol} / 1$

Table 1 Intellectual phenotype of PKU patients determined by the Binet IQ score and World Health Organization ratings.

\begin{tabular}{lcr}
\hline $\begin{array}{l}\text { Intellectual } \\
\text { phenotype }\end{array}$ & $\begin{array}{c}\text { World Health } \\
\text { Organization }\end{array}$ & Binet IQ score \\
\hline Normal & Apparently normal & $>85$ \\
Borderline & Level 0 & $68-85$ \\
Mild & Level 1 & $52-67$ \\
Moderate & Level 2 & $36-51$ \\
Severe & Level 3 & $20-35$ \\
Profound & Level 4 & $<20$ \\
\hline
\end{tabular}


$\mathrm{MgCl}_{2}, 1 \mu \mathrm{mol} / 1$ of each primer, and 1.6 units of Taq polymerase (Biotech, Australia, Perth) in total reaction volume of $100 \mu \mathrm{l}$.

Exons 7 and 8 were amplified by PCR using 35 cycles of $95^{\circ} \mathrm{C}$ for 105 seconds, $64^{\circ} \mathrm{C}$ for 150 seconds, and $72^{\circ} \mathrm{C}$ for 180 seconds, with primers $\mathrm{DD}$ and EE (fig $1 \mathrm{~A}$ ). Exon 12 was amplified with primers $A$ and $B^{12}$ (fig $1 B$ ). PCR conditions were as above but with an annealing temperature of $56^{\circ} \mathrm{C}$.

Mutations in exons 7 and 12 were screened for by double stranded direct sequencing as the exons were only 136 and $116 \mathrm{bp}$ long respectively. PCR products from each patient were electroeluted from $0.8 \%$ agarose gels and sequenced using a method incorporating the detergent NP40. ${ }^{13}$

Screening for the R158Q (exon 5) mutation $^{14}$ was performed by creating an $M s p \mathrm{I} /$ HpaII restriction enzyme site during PCR amplification. ${ }^{15}$ PCR products amplified using primers $5 \mathrm{~B}$ and $5 \mathrm{C}$ were digested with the restriction enzyme HpaII using manufacturer's conditions and fragments were separated by electrophoresis on a $3 \%$ Nusieve agarose gel $1 \times$ TBE buffer (TBE: $0.045 \mathrm{~mol} / 1$ Tris-borate, $1 \mathrm{mmol} / 1$ EDTA). PCR conditions were as above but annealing was at $56^{\circ} \mathrm{C}$. When DNA from a patient was found to contain this restriction enzyme site, exon 5 was amplified and sequenced to confirm the presence of the mutation (fig 1C).

Only one member of each family was initially screened for these mutations as de-

A

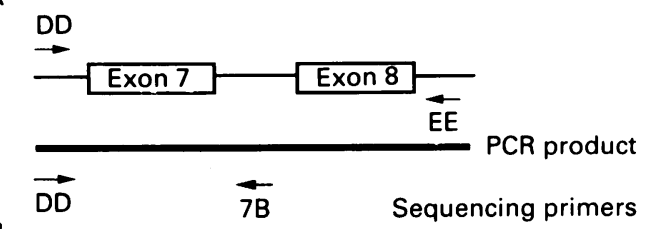

A
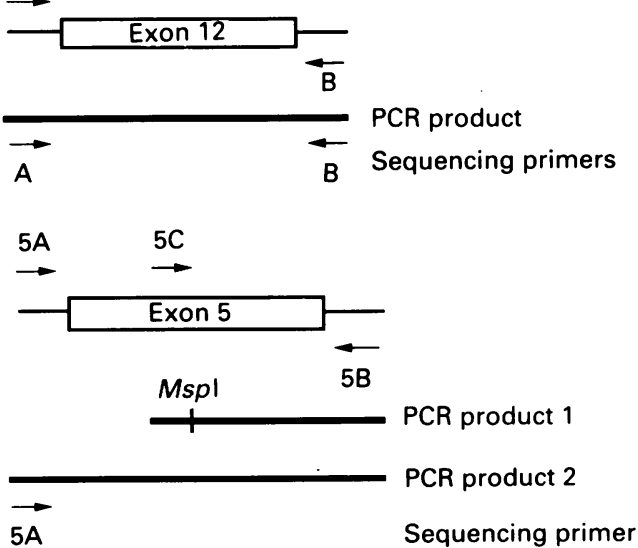

Figure 1 Position of oligonucleotides for amplification and direct sequencing of PCR products. $(A)$ Primers $D D$ and $E E$ are used to amplify from intron 6 to intron 8 , and $D D$ and $7 B$ are used to sequence exon 7 both sense and antisense respectively. (B) Primers $A$ and $B$ are used to amplify from intron 11 to intron 12 and are used to sequence exon 12 both sense and antisense respectively. (C) Primers $5 C$ and $5 B$ are used to amplify part of exon 5. A mismatch in primer $5 C$ created a MspI/HpaII restriction enzyme site in the $P C R$ products if the $R 158 Q$ mutation was present.

Primers $5 A$ and $5 B$ are used to amplify from intron 4 to intron 5 and $5 A$ was used to sequence the sense strand of exon 5 to confirm the presence of the mutation. scribed above. If a mutation was found the DNA from all affected sibs was sequenced to be certain that the sibs had the same genotype. The primers used for PCR amplification and sequencing are as follows:

DD 5' CTCCTAGTGCCTCTGACTCA 3' EE 5' TGGGCTCAACTCATTAGAGA 3' 7B 5' ACCAGCCAGCAAATGAACCC $3^{\prime}$ A 5' ATGCCACTGAGAACTCTCTT 3' B 5' AGTCTTCGATTACTGAGAAA 3' 5A 5' TCATGGCTTTAGAGCCCCCA 3' 5B 5' TCATGCTGGTATTTTCATCC 3' 5C 5' ATCCTGTGTACCGTCCAAGC 3'.

\section{Results}

All mutations examined in the study by Okano et $a l^{\dagger}$ were screened for in this sample of untreated patients. Exons 7 and 12 were sequenced, allowing the detection of all mutations in these regions. This resulted in the identification of a new mutation, $R 408 \mathrm{Q},{ }^{16}$ in one patient. The R158Q mutation (exon 5) was screened for by site directed mutagenesis and restriction enzyme digestion. During this study we have defined the mutation in $54 \%$ of the alleles of this group of PKU patients, 45 mutations out of a total of 84 mutant alleles (two alleles per family). Sequencing exons 7 and 12 alone identified mutations in over half of the total alleles.

The frequencies of the mutant alleles in this population were calculated (table 2). These frequencies are similar to those found in other populations with the donor splice site mutation in intron 12 and the R408W mutation in exon 12 being the most common. An example of exon 7 sequencing is seen in fig 2 showing the mutation R252W. During the sequencing of exon 7 the polymorphism $\mathrm{V} 245 \mathrm{~V}^{29}$ was found in a heterozygous state in 11 of the patients, resulting in a frequency of $13 \%$.

Both mutant alleles have been determined in 12 families and an example of the two mutations found in one family is shown in fig 3 . One mutant allele has been identified in 21 families leaving nine families where we have not yet identified any mutations. The genotypes and intellectual phenotypes of the 12 families in which both mutations are known is shown in table 3. These results were compared to the predicted enzyme activity of phenylalanine hydroxylase for each genotype from expression studies. ${ }^{9}$

Table 2 Frequencies of the mutant alleles in this group of $P K U$ patients.

\begin{tabular}{llccc}
\hline Exon & Mutation & $\begin{array}{c}\text { No of } \\
\text { alleles }\end{array}$ & $\begin{array}{c}\text { Frequency of } \\
\text { alleles (\%) }\end{array}$ & Reference \\
\hline 5 & R158Q & 1 & $1 \cdot 2$ & 14,17 \\
7 & R243ter & 2 & $2 \cdot 4$ & 18 \\
7 & R252W & 2 & $2 \cdot 4$ & 19,20 \\
7 & R261Q & 4 & $4 \cdot 8$ & 14 \\
7 & G272ter & 1 & $1 \cdot 2$ & 21,22 \\
7 & E280K & 1 & $1 \cdot 2$ & 19,23 \\
7 & P281L & 1 & $1 \cdot 2$ & 24,25 \\
7 & IVS7nt1 & 2 & $2 \cdot 4$ & 26 \\
12 & R408Q & 1 & $1 \cdot 2$ & 16 \\
12 & R408W & 17 & $20 \cdot 2$ & 27 \\
12 & IVS12nt1 & 13 & $15 \cdot 5$ & 28 \\
Total & & 45 & $53 \cdot 6$ & \\
\hline
\end{tabular}

Frequencies are based on one affected subject from each family, therefore 84 mutant alleles. 


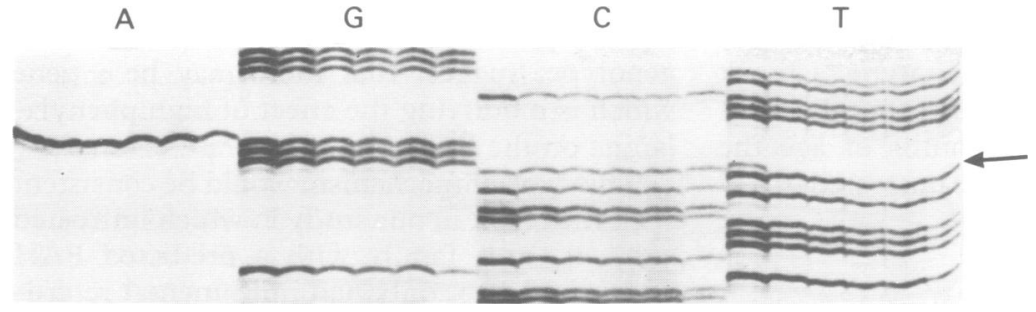

Figure 2 Sequencing of six PKU patients for exon 7 mutations. Acrylamide gel was run with the $A$ nucleotides for the six different patients next to each other, then the $G$, $C$, and $T$ nucleotides respectively so that mutations are easy to identify. An extra band in the $T$ track of the first patient is indicated by an arrow. In this patient there are two bands at this position of the sequencing, the normal $C$ band and the extra $T$ band. Both are of half intensity indicating that this patient has a heterozygous $C$ to $T$ change. This is the R252W mutation.

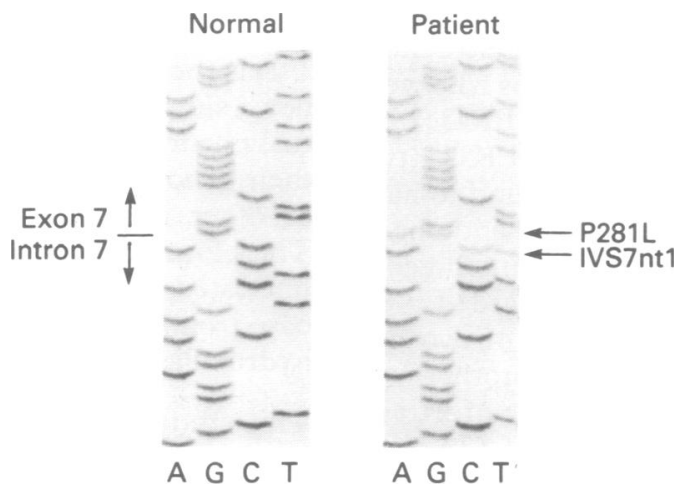

Figure 3 Genotyping by direct sequencing of double stranded PCR products from normal and $P K U$ patient DNA. Sequence of the antisense strand of exon 7 of a patient (family 30, table 3) showing both mutations of the PAH gene. The heterozygous $G$ to $A$ change is the P281L mutation (on the sense strand: $C$ to $T$ ) and the heterozygous $C$ to $T$ change is the IVS7nt 1 mutation (on the sense strand: $G$ to $A$ ). Therefore the genotype of this patient is IVS7nt 1:P281L.

Okano et al found a good correlation between predicted enzyme activity (based on genotype) and biochemical phenotype (from load tests). In our study, there is some correlation between intellectual phenotype and expected PAH activity (based on genotype) with a lower expected PAH activity giving more severe mental retardation. Although in most cases a zero predicted activity correlated with profound mental retardation, the affected sibs of family 1, all found to be homozygous for the IVS12ntl mutation, were only mildly retarded.

Table 3 Comparison of predicted PAH activity based on genotype with intellectual phenotype.

\begin{tabular}{rllc}
\hline Family & Genotype & $\begin{array}{l}\text { Intellectual phenotypes of affected } \\
\text { sibs }\end{array}$ & $\begin{array}{c}\text { Predicted PAH } \\
\text { activity of } \\
\text { genotype }\end{array}$ \\
\hline 2 & R408W:R408W & Profound & 0 \\
27 & IVS12nt1:R408W & Profound, severe-profound & 0 \\
1 & IVS12nt1:IVS12nt1 & Mild, mild, moderate & 0 \\
22 & IVS12nt1:R243ter & Profound & 0 \\
42 & IVS12nt1:E280K & Profound* & $1 \cdot 5$ \\
7 & IVS12nt1:R261Q & Profound & 15 \\
37 & IVS12nt1:R261Q & Profound & 15 \\
24 & IVS12nt1:R261Q & Moderate & 15 \\
3 & R408W:R261Q & Borderline*, moderate† & Unknown \\
8 & IVS12nt1:G272ter & Moderate & Unknown \\
25 & R408W:R252W & Moderate & Unknown \\
30 & IVS7nt1:P281L & Moderate & \\
\hline
\end{tabular}

* Unsuccessful treatment in late childhood.

Dead sib, no DNA studied.

$\ddagger$ Results of Okano et al. ${ }^{9}$ Predicted activity of the PAH enzyme for each genotype is calculated

from expression studies of each mutation and expressed as a percentage of control levels.
The mutation IVS $12 \mathrm{nt}^{28}$ is a $\mathrm{G}$ to A substitution at the donor site of intron 12 causing incorrect splicing of the mRNA resulting in the loss of exon 12 and a protein which is inactive. ${ }^{30}$ Therefore, subjects homozygous for this mutation are expected to have zero activity of the PAH enzyme and when studied by load tests are found to have a classical PKU phenotype. 'Classical PKU' was historically defined as severe mental retardation without treatment. ${ }^{10}$ Subjects with no activity of the PAH enzyme would therefore be expected to have profound mental retardation. Two of the three sibs of family 1 (table 3 ), homozygous for this mutation, were only mildly retarded while the other had moderate mental retardation. This is far less severe than would be expected suggesting that factors other than PAH genotype are affecting the mental phenotype. (These sibs were born between 1937 and 1947, long before treatment was developed.)

If there is a correlation between intellectual phenotype and genotype it would be expected that subjects with the same genotype would have the same phenotype. It is important to note that families 7,37 , and 24 (table 3 ) all have the genotype R261Q:IVS12nt 1; however, they have quite different intellectual phenotypes. Two of the three unrelated subjects have profound mental retardation while the other is only moderately retarded.

As affected sibs are expected to have the same genotype, the range of intellectual phenotypes within the 12 families with more than one affected child was examined (table 4). Although both mutations have not been identified in all families, any mutation identified has been tested for and found to be present in the sibs. Wide ranges in phenotypes were observed within families. For example in family 18 one affected subject is normal while the sib is profoundly retarded, in family 13 one member is profoundly retarded while the other is only mildly retarded, and in family 16 one sib is severely retarded and the other is of borderline intelligence. Thus there is a poor correlation between genotype and intellectual phenotype.

The PKU patients used in this study are untreated as they were born before reliable newborn screening and treatment was available. Although most of the patients were completely untreated, nine of the younger patients were placed on a phenylalanine restrictive diet during late childhood. This treatment was

Table 4 Range of phenotypes of the affected sibs in the 12 families with more than one affected subject.

\begin{tabular}{|c|c|c|}
\hline Family & Genotype & Phenotypes of affected sibs \\
\hline 1 & IVS12nt1:IVS12nt 1 & Mild, mild, moderate \\
\hline 27 & IVS12nt1:R408W & Severe-profound, profound \\
\hline 3 & R261Q:R408W & Borderline*, moderate $\dagger$ \\
\hline 13 & IVS12ntl:unknown & Profound, mild \\
\hline 16 & IVS12nt1:unknown & Borderline, severe \\
\hline 34 & IVS12nt1:unknown & Mild, moderate, profound $\dagger$ \\
\hline 12 & R408W:unknown & Moderate, severe-profound \\
\hline 29 & R408W:unknown & Mild-borderline, profound* \\
\hline 18 & R408W:unknown & Normal, profound $\dagger$ \\
\hline 19 & IVS7nt1:unknown & $\begin{array}{l}\text { Moderate, moderate, } \\
\text { severe-profound }\end{array}$ \\
\hline $\begin{array}{r}4 \\
21\end{array}$ & $\begin{array}{l}\text { Unknown } \\
\text { Unknown }\end{array}$ & $\begin{array}{l}\text { Normal, normal } \\
\text { Normal, moderate }\end{array}$ \\
\hline
\end{tabular}

* Unsuccessful treatment in late childhood.

† Dead sib, no DNA studied. 
ceased soon afterwards when it did not improve the patients' mental phenotype (asterisk in tables 3 and 4). Kang et $a l^{31}$ found that if treatment started after 8 months of age the average IQ was the same as untreated PKU patients.

\section{Discussion}

In our study we have 12 families with more than one affected PKU patient. Within a family the untreated affected sibs have a wide range of phenotypes (table 4). The phenomenon of untreated PKU patients with the same genotype having different intellectual phenotypes has been observed before within families. In one family a mentally retarded 4 year old was identified as having PKU. Screening of his sibs showed that two older sibs who were of normal intelligence also had PKU. ${ }^{32}$ In another family three sibs with PKU (two untreated and one treated) were found to have identical genotypes by haplotyping and one of these untreated sibs was of normal intelligence while the other was severely retarded. ${ }^{33}$ In another study the Binet IQ scores of two sibs with PKU was examined. One brother was mentally retarded with an IQ score of 21 and the other was normal with an IQ of $132 .^{8}$

As well as expanding on the already documented intrafamilial phenotypic variation seen in PKU we have also shown that there is interfamilial phenotypic variation with unrelated subjects having the R261Q:IVS12nt1 genotype showing quite different intellectual phenotypes (families 7, 37, and 24 in table 3). This difference between the intellectual phenotypes of subjects with the same genotype both within and between families introduces great difficulties for the expectation of treatment based on genotype.

Non-concordant phenotypes of affected sibs with the same genotype suggest that the intellectual phenotype of PKU patients can be influenced or altered by additional genetic loci and epigenetic factors. ${ }^{334}$ Ledley $^{34}$ warned that because of these additional factors and the effect of variation in diet, the mutant genotype may not predict the mental phenotype. DiSilvestre $e t a l^{33}$ found that the genotype predicted the biochemical phenotype (load tests) but not the clinical phenotype (mental retardation). This is consistent with our observation that the intellectual phenotypes of our untreated patients did not correlate as well with the predicted activities based on genotype as the phenotypes in the study of Okano et al which were based on biochemical load tests.

If additional genetic factors are responsible for the variation seen in the intellectual phenotype of untreated PKU patients with the same genotype, we would predict that they are acting at the second step of a postulated two step model. In the first step the mutant genotype leads to raised phenylalanine levels and in the second step the high phenylalanine levels lead to brain damage. The first step, which is where the effect of diet takes place, can be studied using load tests and correlates well with the genotype. ${ }^{9}$ Our results, which show that intel- lectual phenotype does not correlate with genotype, suggest that there may be a gene which is modifying the effect of high phenylalanine on the brain.

This type of mechanism would be consistent with the result in our study in which untreated subjects, in a family with a predicted PAH activity of zero, only had mild mental retardation. This may also explain why there was no correlation between serum phenylalanine levels and intellectual phenotypes in our patients. ${ }^{3}$ The results of Trefz et $a l^{10}$ which could not find a correlation between enzyme activity and the intellectual phenotype of untreated patients would also be explained. Further studies are needed to confirm and then possibly identify this putative gene modulating the effect of high phenylalanine.

It is the conclusion of this study that there is not a simple correlation between the intellectual phenotype of untreated PKU patients and their genotype and that environmental factors or other genes are affecting the phenotype. Therefore it is not possible to predict the untreated intellectual phenotype of a patient based on the genotype of the phenylalanine hydroxylase gene.

This study was supported by grants from the National Health and Medical Research Council and the Victorian Health Promotion Foundation.

1 Guttler F. Hyperphenylalaninemia: diagnosis and classification of the various types of phenylalanine hydroxylase
deficiency in childhood. Acta Paediatr Scand Suppl 1980;280:1-80.

2 Pitt D, Wilmot AE. Phenylketonuria in Victoria. Med $\mathcal{f}$ Aust 1965;1:33-9.

3 Pitt D. The natural history of untreated phenylketonuria. Med f Aust 1971;1:378-83.

4 Pitt $D$. Phenylketonuria with normal intelligence: report of two cases. Aust $\mathcal{F}$ Ment Res 1971;1:160-3.

5 Eisensmith RC, Woo SLC. Molecular basis of phenylketonuria and related hyperphenylalanemias: mutations and polymorphisms in the human phenylalanine hydroxylase gene. Hum Mutat 1992;1:13-23.

6 Scriver CR, Kaufman S, Woo SLC. The hyperphenylalaninemias. In: Scriver CR, Beaudet A, Sly W, Valle D, eds. The metabolic basis of inherited disease. 6 th ed. New York: McGraw-Hill, 1989:495-546.

7 Tyfield LA, Meredith AL, Osborn MJ, et al. Genetic analysis of treated and untreated phenylketonuria in one family. $\mathcal{F}$ Med Genet 1990;27:564-8.

8 Perry TL, Hansen S, Tischler B, Bunting R, Diamond S. Glutamine depletion in phenylketonuria: a possible cause of the mental defect. $N$ Engl $₹$ Med 1970;282:761-6.

9 Okano Y, Eisensmith RC, Guttler F, et al. Molecular basis of phenotype heterogeneity in phenylketonuria. $N$ Engl $\mathcal{F}$ of phenotype heterogen
Med 1991;324:1232-8.

10 Trefz FK, Lichter-Konecki U, Konecki DS, Schlotter M, Bickel H. PKU and non-PKU hyperphenylalaninemia: differentiation, indication for therapy and therapeutic results. Acta Paediatr Jpn 1988;30:397-404.

11 Miller SA, Dykes DD, Polesky HF. A simple salting out procedure for extracting DNA from human nucleated cells. Nucleic Acids Res 1988;16:1215.

12 DiLella AG, Huang WM, Woo SLC. Screening for phenylketonuria mutations by DNA amplification with the polymerase chain reaction. Lancet 1988;i:497-9.

13 Bachmann B, Luke W, Hunsmann G. Improvement of PCR amplified DNA sequencing with the aid of detergents. Nucleic Acids Res 1990;18:1309.

14 Okano Y, Wang T, Eisensmith RC, Steinmann B, Gitzelmann R, Woo SLC. Missense mutations associated with mann R, Woo SLC. Missense mutations associated with hydroxylase gene. Am $\mathcal{F}$ Hum Genet 1990;46:18-25.

15 Eiken HG, Odland E, Boman H, Skejelkvale L, Engebretsen LF, Apold J. Application of natural and amplification sen LF, Apold J. Application of natural and amplification
created restriction sites for the diagnosis of PKU mutacreated restriction sites for the diagnosis
tions. Nucleic Acids Res 1991;19:1427-30.

16 Ramus SJ, Forrest SM, Saleeba JA, Cotton RGH. CpG hotspot causes second mutation in codon 408 of the hotspot causes second mutation in codon 408 of the
phenylalanine hydroxylase gene. Hum Genet 1992;1:1548 .

17 Dworinczak B, Aulehla-Scholz C, Horst J. Phenylketonuria: detection of a frequent haplotype 4 allele mutation. Hum Genet 1989;84:95-6.

18 Wang T, Okano Y, Eisensmith RC, et al. Molecular genetics of PKU in eastern Europe: a nonsense mutation 
associated with haplotype 4 of the phenylalanine hydroxylase gene. Somat Cell Mol Genet 1990;16:85-90.

19 Abadie V, Lyonnet S, Maurin N, et al. CpG dinucleotides are mutation hotspots in phenylketonuria. Genomics 1989;5:963-9.

20 Okano Y, Wang T, Eisensmith RC, Woo SLC. PKU mutations among Caucasians. Am $\mathcal{f}$ Hum Genet 1989;45:A211.

21 Svensson E, Andersson B, Hagenfeldt S. Two mutations within the coding sequence of the phenylalanine hydroxylase gene. Hum Genet 1990;85:300-4.

22 Apold J, Eiken HG, Odland E, et al. A termination prevalent in Norwegian haplotype no 7 PKU genes. Am $\mathcal{F}$ Hum Genet 1990;47:1002-7.

23 Lyonnet S, Caillaud C, Rey F, et al. Molecular genetics of phenylketonuria in Mediterranean countries: a mutation associated with partial phenylalanine hydroxylase deficiency. Am f Hum Genet 1989;44:511-17.

24 Okano Y, Wang T, Eisensmith RC, et al. Phenylketonuria missense mutations in the Mediterranean. Genomics 1991;9:96-103.

25 Dworinczak B, Grudda K, Stumper J, Bartholome K, Aulehla-Scholz C, Horst J. Phenylalanine hydroxylase gene: novel missense mutation in exon 7 causing phenylketonuria. Genomics 1991;9:193-9.

26 Dianzani I, Forrest SM, Camaschella C, Saglio G, Ponzone A, Cotton RGH Screening for mutations in the phenyla$A$, Cot lanine hydroxylase gene from Italian patients with phenylketonuria by using the chemical cleavage method:
new splice mutation. Am $\mathcal{F}$ Hum Genet 1991;48:631-5.
27 DiLella AG, Marvit J, Brayton K, Woo SLC. An aminoacid substitution involved in phenylketonuria is in linkage disequilibrium with DNA haplotype 2. Nature 1987;327:333-6.

28 DiLella AG, Marvit J, Lidsky AS, Guttler F, Woo SLC. Tight linkage between a splicing mutation and a specific DNA haplotype in phenylketonuria. Nature 1986; 322:799-803.

29 Dworinczak B, Aulehla-Scholz C, Horst J. Phenylalanine hydroxylase gene: silent mutation uncovers evolutionary hydroxylase gene: silent mutation uncovers evolutionary

30 Marvit J, DiLella AG, Brayton K, Ledley FD, Robson $\mathrm{KJH}$, Woo SLC. GT to AT transition at a splice donor site causes skipping of the preceding exon in phenylketonuria Nucleic Acids Res 1987;15:5613-28.

31 Kang ES, Sollee ND, Gerald PS. Results of treatment and termination of the diet in phenylketonuria (PKU). Pediatrics 1970;46:881-90.

32 Bessman SP, Due Logue D, Wapnir RA. Phenylketonuriacertainty versus uncertainty. In: Richards BW, ed. Proceedings of the first congress of the international association for the scientific study of mental deficiency. Montpellie France: Micheal Jackson Publishing Co, 1967:182-93.

33 DiSilvestre D, Koch R, Groffen J Different clinical manifestations of hyperphenylalaninemia in three siblings with festations of herphe siblings with Genet 1991;48:1014-16.

34 Ledley FD. Clinical application of genotypic diagnosis for phenylketonuria: theoretical considerations. Eur $\mathcal{F}$ Pediatr $1991 \cdot 150: 752-6$. 